\title{
Lessons learned from a decade implementing Comprehensive Sexuality Education in resource poor settings: The World Starts With Me
}

\author{
Ine Vanwesenbeeck ${ }^{\mathrm{a}, \mathrm{b}}$, Judith Westeneng ${ }^{\mathrm{a}, \mathrm{c}}$, Thilly de Boer ${ }^{\mathrm{a}}$, Jo Reinders ${ }^{\mathrm{a}}$ and \\ Ruth van Zorge ${ }^{a}$
}

aDepartment of International Programmes, Rutgers, Utrecht, The Netherlands; ${ }^{b}$ Department of Interdisciplinary Social Sciences, Utrecht University, Utrecht, The Netherlands; 'Department of Cultural Anthropology and Development Studies, Radboud University, Nijmegen, The Netherlands

\begin{abstract}
Today, more than half of the world population is under the age of 25 years and one in four is under age 18. The urgency of expanding access to Comprehensive Sexuality Education (CSE) notably for children and young people in Africa and Asia is greater than ever before. However, many challenges to the implementation and delivery of CSE in resource poor settings have been identified in the literature. CSE's effectiveness could be strongly improved if these challenges were better met. This paper aims to contribute to those muchneeded improvements by sharing lessons learned from a decade of implementation of one particular CSE programme, The World Starts With $\mathrm{Me}$, among various populations in 11 low income countries in Africa and Asia. The aims, content, reach and effectiveness of the programme are described. Next, the challenges for implementation and delivery at student, teacher, school and context level are discussed with reference to the wider knowledge base in this area. Finally, suggestions are provided for ways forward including the increased sensitivity of programmes for normative and practical barriers to sexual health, further advancement towards gender transformativity, a far-reaching expansion of comprehensive forms of teacher training and coaching, and a serious stepping-up of multilevel 'whole school' approaches.
\end{abstract}

\section{ARTICLE HISTORY}

Received 14 July 2015

Accepted 19 October 2015

\section{KEYWORDS}

Comprehensive Sexuality Education; critical pedagogy; whole school approach; Africa; Asia

\section{Introduction}

Today, more than half of the world population is under 25 years of age and one in four is under age 18 (UNFPA 2014). Eighty-five per cent of young people between 15 and 24 years of age are living in the developing world (UN 2006). At present, the majority (60\%) of youth live in Asia, but in the coming decades it is particularly the African continent that will see an unprecedented growth in the number of children under 18, with their share in the total population set to rise to $40 \%$ by 2050 (UNICEF 2014). The urgency of expanding access to 
Comprehensive Sexuality Education (CSE) for present and future generations of children and young people in Africa and Asia is greater than ever before. CSE has great potential to provide young people with the necessary information about their bodies and sexuality, to reduce misinformation, shame and anxiety, and to improve their abilities to make safe and informed choices about their sexual and reproductive health (e.g. Boonstra 2011; UNFPA 2010). Access to CSE may contribute to a reduction in early childbirth, (unsafe) abortion, sexual violence and sexual ill health, and to the promotion of gender equality and young people's overall sexual and reproductive health and rights (e.g. WHO 2011). It could support adolescents, not least girls, in a safe passage to adulthood and in reaching their full potential in educational achievement, earning capacity and societal participation. Adequate access to CSE could thus contribute to the socioeconomic development of countries.

Although sexuality education remains controversial, there is growing evidence that good quality CSE has positive effects on sexual knowledge, attitudes, communication skills and certain sexual behaviours (e.g. Kirby 2011; UNESCO 2009). In comparison to less comprehensive programmes, CSE has been shown to contribute more adequately to gains in young peoples' sexual health (Fine and McClelland 2006; Haberland and Rogow 2015; Kirby 2008; McCave 2007; Trenholm et al. 2007; Underhill, Montgomery, and Operario 2007). However, evidence of the (long-term) effects of CSE on young people's protective behaviours and certainly on biomarkers, such as the prevalence of STIs/HIV and teenage pregnancies, is at most only moderately strong, often even weak (Doyle et al. 2010; Kirby 2007; Kohler, Manhart, and Lafferty 2008; UNFPA 2010; Yankah and Aggleton 2008). Reasons brought forward to explain these modest results are related to limitations in the content, implementation and delivery of educational programmes, to disabling environments and the complex cultural embeddedness of sexual behaviours, as well as to methodological problems in the studies conducted (Kippax 2003; Michielsen et al. 2010; Vanwesenbeeck 2011). Overall, the field has been criticised for wrongfully breathing 'pan-optimism' (Lesko 2010) and for the incorrect underlying assumption that individual decision-making is the key site of risk minimisation and progress towards sexual health (Bromnick and Swinburn 2003; Dworkin and Ehrhardt 2007).

Notwithstanding other barriers to sexuality education's effectiveness, it has become clear that CSE's effectiveness could be enhanced enormously if the many challenges in implementation and delivery could be better met. This has been argued for the developing (e.g. Harrison et al. 2010; lyer, Clarke, and Aggleton 2014; Ott et al. 2011; Wood and Rolleri 2014) as well as the developed world (e.g. Cushman et al. 2014; Schutte et al. 2014). It is the purpose of this paper to contribute to these much needed improvements by sharing lessons learned from a decade of implementation of the CSE programme, The World Starts With Me, among various populations in 11 resource poor countries in Africa and Asia.

First, a short description of the programme, standard implementation procedures and overall reach during the last decade is provided. Next, the results of evaluation studies combined with practice-based insights are presented and discussed in reference to the wider knowledge base in this area. Finally, we offer suggestions for ways forward.

\section{The World Starts With Me: the programme in brief}

The World Starts With Me is an innovative, computer-based, CSE programme that uses a rights- and evidence-based approach and is available on CD-ROM, the Internet and in print. 
The programme targets in- and out-of-school youth between the ages of 12-19 years and combines education on SRHR with building IT skills and creative expression. The programme was originally developed with and for secondary school students in Uganda in 2003, in close collaboration with Rutgers WPF (a Dutch centre of expertise on sexuality and sexual and reproductive health and rights, now known as Rutgers), Butterfly Works, SchoolNet Uganda and teachers and students of pilot schools. Guided by Rutgers WPF, the original Ugandan programme was subsequently adapted to the socio-cultural context of Kenya in 2005, and from 2007 on to the context of Indonesia, Indonesian Papua, Thailand, Vietnam, Pakistan and Ethiopia. At the time of writing, adaptations are being finalised in Ghana, Malawi, Bangladesh and Burundi and are being planned for Zambia and Maasai youth in Kenya. The World Starts With $\mathrm{Me}$ is usually implemented in secondary schools, but adapted versions have also been developed for other settings such as primary schools, teacher trainings, health care settings working with young people born and living with HIV, young people's prisons and schools for young people with hearing and visual impairments. In 2010, the programme was recognised in UNESCO's International Guidance for Sexuality Education as a model programme for CSE programmes (UNESCO 2009), while in 2004 The World Starts With Me won the global Golden Nica Award for electronic and interactive innovation. Most schools use the electronic version, although lack of computers and electricity may be reasons for some schools (notably in Uganda and Ghana) to decide on the paper version. Sometimes LCD projectors are used. In Papua Indonesia lessons are recorded on video for use among hearing impaired youth.

In about half of the countries involved, The World Starts With Me has only been piloted so far and its reach is still limited. In Ghana, for instance, 35 teachers have been trained and 1250 pupils reached. In Bangladesh, implementation is still in its infancy: only 4 teachers have been trained and 60 pupils reached. In other countries, implementation has been much broader. In Indonesia, for instance, more than 200 teachers have been trained and 16,500 pupils reached. In Kenya, equivalent figures amount up to over 400 and over 58,000, respectively. Implementation reach in Uganda compares to that of Kenya.

\section{Core didactics and content}

The The World Starts With Me programme aims to increase young people's knowledge, develop their attitudes, enhance their skills and increase their self-esteem in order to empower them to make responsible choices concerning relationships, sexuality and sexual and reproductive health. The programme's didactics are learner-centred and rights-based. Youth involvement is an integral aspect of the programme's development as well as its implementation. Instead of merely being recipients, the active participation of students is key in empowering them to become capable of representing themselves and making their own decisions. Teachers are supposed to facilitate the empowerment process rather than teach content. This model of learning is closely aligned with rights-based pedagogy and what has been called 'critical pedagogy' (e.g. Kincheloe 2008), aiming to improve young people's lives not merely through behavioural change but also through cognitive and social transformation. The didactic vision is also aligned with current educational strategies such as outcomes-based learning and competency-based education (e.g. Power and Cohen 2005).

The programme's content is structured according to a logical sequence of events and consists (depending on the setting) of 14-17 lessons, divided into four sections, including - among others - modules on self-awareness, decision-making, identity and sexual 
development, the role of the social environment (including media), gender and rights, sex and love (orientation, pleasure), sexual health problems, and life skills. During implementation, links to students'families and communities are actively sought, for instance in the form of homework assignments that include communication with parents and the community. Throughout the programme, young people are mobilised to take action and advocate for a supportive environment regarding the sexual and reproductive health and rights for young people in their families and their community. The curriculum closes with an exhibition at which young people show fellow pupils, parents and the community the results of the class efforts, such as slogans, posters, role plays and action plans.

Each specific version of The World Starts With Me addresses the needs of the young people as identified during a needs assessment in that specific culture and setting. If necessary, additional lessons on specific topics are added. For instance, the Indonesian programme version, entitled DAKU!, includes a session on stress management and a lesson on drug use in relation to preventing HIV infection, while the Thai programme version stresses the needs of LGBT youth and helps boys in particular to more openly communicate their emotions and be empathic. In Kenya and Ethiopia, an extra lesson was added on culture which specifically addresses child marriage, gender-based violence and female genital mutilation. In Ethiopia, a lesson about drugs, including khat, was also added. The programme versions used in teacher training explicitly address the methodology and didactics underlying learner-centred provision of CSE in primary and secondary schools. Sometimes, specific topics have been considered redundant and have been deleted in adapted versions.

\section{Standard implementation procedures}

Although they share the same basic principles, approaches and components, each version of The World Starts With Me has been developed using a similar protocol of Intervention Mapping, ${ }^{1}$ with substantial youth participation. The process of implementation encompasses various phases, including an initial intensive sensitisation process within schools as well as among parents and the wider community to facilitate later adoption, development and adaptation, the training of teachers/educators from pilot schools, pilot implementation, monitoring and evaluation, and final adaptation to a local version. At the start, a local coordinating implementing agency is selected and trained. The Implementing Agency conducts a local situation analysis and needs assessment, selects pilot schools/institutions and establishes a working group of young people/students and teachers/educators from the pilot schools or institutions. Implementing agencies set certain criteria for schools to select teachers (e.g. being sex-ed experienced, youth-friendly and open minded regarding sexuality), but schools often appoint teachers for practical reasons, not taking these criteria into account. Throughout the process, the implanting agency is guided by an advisory board consisting of key stakeholders such as the ministry of education, the ministry of health, the National AIDS Commission, family planning associations, and experts from universities, religious bodies and UNESCO. When the final local programme version has been developed, pilot educators are trained as master trainers and upscaling starts. In a number of countries, roll-out activities are presently underway. In Burundi, The World Starts With Me has recently been selected for nationwide implementation. 


\section{Evidence of effectiveness}

In four countries (Uganda, Kenya, Thailand and Indonesia), the effects of the programme have been assessed using a quasi-experimental evaluation design including pre- and posttests among intervention and comparison groups (Leerlooijer 2013; Rijsdijk 2013; Rutgers WPF 2011). In Uganda, and to a lesser extent in Thailand and Indonesia, positive effects have been found for important aspects and determinants of safe sex behaviour. The World Starts With Me has proved effective in terms of relevant knowledge gain (e.g. towards pregnancy), positive attitudes (e.g. towards condom use), self-efficacy (e.g. in condom use) and intentions (e.g. to delay first intercourse and to seek sexual health services). Notably in Uganda, myths concerning pregnancy decreased, perceived social norms towards delaying sex improved and self-efficacy in dealing with sexual violence increased. In Thailand, the programme has contributed to students' self-disclosure about sensitive, sexuality-related topics. No changes have been found in terms of delay of intercourse or condom or contraceptive use. In Kenya, no effects were found at all, except for the unfortunate one that attitudes towards condom use became more negative. As in many other studies evaluating CSE programmes, it was concluded that the effects of The World Starts With Me on outcomes related to individual health determinants were, at best, modest (Rutgers WPF 2011).

These evaluation studies were based theoretically on theories of individual behaviour change, notably the theory of planned behaviour and the health belief model. As a consequence, outcome measures were mostly limited to individual health behaviours and related attitudes and intentions. Additional process evaluations (e.g. Browes 2014; van Lieshout 2013; van der Stok 2014) as well as observations made during programme implementation in various countries have looked at a wider range of outcomes. A contrast is evident between the modest results on health-related attitudes and behaviours in the effects evaluations on the one hand, and the positive evaluations reported by all relevant stakeholders in qualitative studies on the other hand. Responses in Focus Group Discussions and interviews show that the programme is perceived as comprehensive and adequately combines learning and fun. An evaluation in Ugandan schools (van Enck 2011) indicates positive effects on class atmosphere and relationships between boys and girls. In general, many students report positive outcomes that do not directly relate to sexual health behaviours.

Good examples in this respect can be drawn from a qualitative study recently conducted in Ethiopia (Rutgers 2014) that developed an inventory of students' personal perceptions of the programme's effects using Stories of Change. Students notably reported significant changes in self-confidence, awareness and acceptance: 'Now I have confidence! I used to be shy and was afraid to speak out in class, but not anymore' (girl 15 years) and 'I understand why my body changes, and I feel confident and relaxed about it' (girl 15 years). Others reported more positive feelings regarding direction in life: 'Having a dream is like seeing light in the dark. It helps you to have a goal in life' (boy 17 years) and 'Life is full of hardship. I learned from the programme that if I have a plan for the future, it will help me focus, grow, and reach my goal: being a politician' (boy 17 years). In addition, young people's advocacy ambitions and skills were said to be boosted: 'We can't discriminate against people living with HIV. I want to liberate people from that stigma' (girl 15 years) and 'Teenage pregnancy should be prevented. I want to teach people about the importance of contraceptives and condoms' (girl 17 years). 
What the programme can achieve in terms of stimulating advocacy ambitions among young people is also eminently exemplified in the fact that a The World Starts With Me Alumni Youth Advocacy Network has been thriving in Kenya since 2005. This suggests that when sexuality education is well introduced in a community, it may well have stimulating effects on young people's wider participation. In Ethiopia, Browes (2014) also found that students reported increased self-confidence after participation in the programme as well as the development of new skills including computer, language, presentation and planning skills. Importantly, outcomes were not limited to The World Starts With Me students. Teachers and NGO workers involved in the programme also said they had learned a lot about sexual and reproductive health and rights, and had developed a better appreciation of the importance of comprehensive and participatory sexuality education. A study of the most significant changes for teachers who participated in the programme in Pakistan (Rana 2014) demonstrated improvements in teachers' confidence, teaching skills, understanding of students' issues, and relationships with students, as well as with their own families and communities. Students also often reported having spoken extensively about the programme with friends and family, which suggests that information is being spread beyond the classroom. In Ghana, Rashid Imoro estimated, in a personal communication, that the indirect beneficiaries of the programme comprise five times as many people as the students who were directly reached by the programme. Although principally advantageous, these so-called spillover effects have, at the same time, been identified as a serious methodological problem when randomised controlled trials are employed to measure programme's effects (Vanwesenbeeck 2011).

The evidence presented here, albeit somewhat anecdotal, strongly suggests that CSE may have benefits beyond individual health. The effective implementation of sexuality education may benefit teacher-student relationships in the classroom, parent-child communication, community norms and school social climate. We agree with Boonstra (2011) in observing that the focus on health behaviours in much of evaluation research provides little insight into how well CSE programmes work to achieve other desired outcomes, such as greater gender equality, critical thinking skills, a sense of confidence and belief in the future, and sexual pleasure. Others writers such as Rotheram-Borus, Swendeman, and Flannery (2009) and Germain, Dixon-Mueller, and Sen (2009) argue that the dominance of a HIV-related public health perspective in sexuality education has seriously limited views of sexuality education as relevant to the attainment of broader goals, such as social health and development, livelihoods, gender equity, emancipation, communication and community well-being. Experience with The World Starts With Me shows that programmes that include issues such as gender norms, psychological and social aspects of sexuality, sexual orientation, sexual expression and pleasure, violence, and individual rights and responsibilities, may well contribute to the attainment of these more general outcomes.

\section{Challenges in programme delivery}

These suggestions of positive effects do not detract from the fact that The World Starts With Me field experimental evaluations (Leerlooijer 2013; Rijsdijk 2013) show modest results in terms of individual health behaviours. These (and other) studies point to implementation challenges (also see Figure 1) which may explain those modest results. Many of these challenges relate to delivery issues. Two specific aspects are focused on here. 


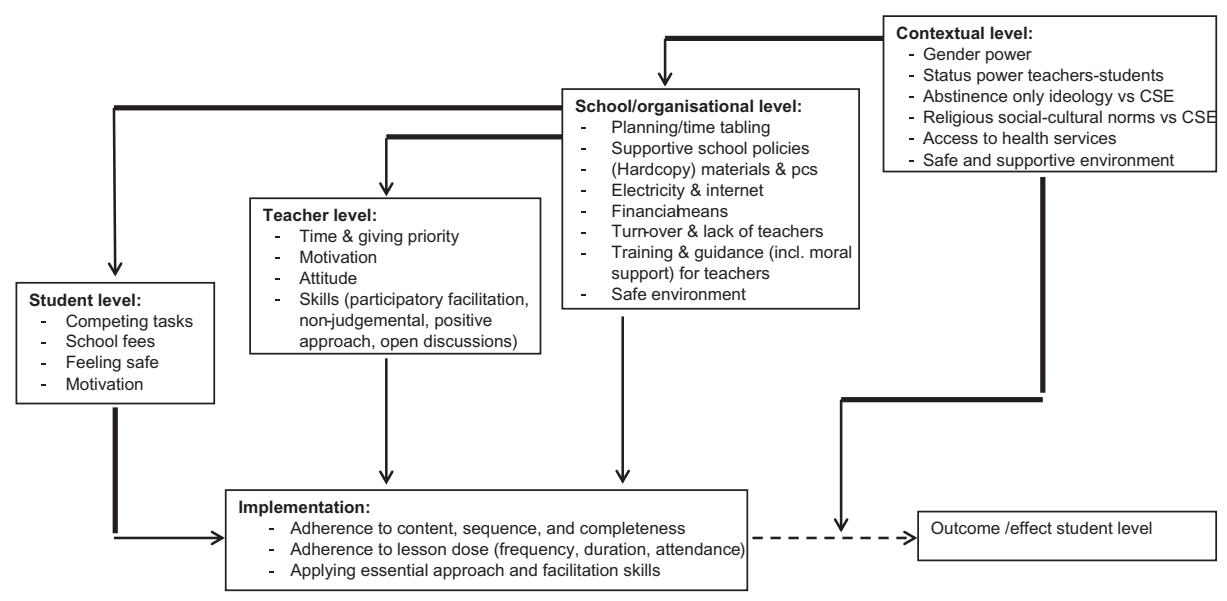

Figure 1. Barriers to CSE implementation and effectiveness. ${ }^{2}$

\section{Programme fidelity}

There is abundant evidence that in many sites The World Starts With Me was or is not being delivered as intended (Browes 2014; van Lieshout 2013; Rijsdijk 2013; Rijsdijk et al. 2013; Rutgers WPF 2011; van der Stok 2014). In most of the implementation sites studied, certain lessons have been skipped or shortened, especially those on sensitive topics such as masturbation, homosexuality and abortion. Teachers often eschew or limit activities related to skills building, such as role plays because they think that students will find them difficult, or because they lack confidence in facilitating them well enough because of large class sizes (cf. Ahmed et al. 2009). Another observation for The World Starts With Me is that lessons often take longer due to the many questions students come to ask once the opportunity arises in the safe atmosphere created by trained programme teachers. In Thailand, where The World Starts With Me has been made part of the formal school curriculum in some schools, implementation fidelity has been relatively high, but only because the Thai project team decided to spread implementation of over two years to make sure that all elements and all lessons could be implemented.

In addition, several practical issues may hamper programme fidelity. Van der Stok (2014) evaluated The World Starts With Me implementation in Malawi and identified a complex network of school-level elements affecting programme fidelity, such as inefficient schedules and planning of lessons, lack of available teacher time, lack of availability of materials and computers, and negative attitudes of staff. In some other contexts, programme implementation of a computer-led programme has been strongly hampered by non-availability and lack of access to electricity and to the Internet. These findings are in line with many other studies conducted on sexuality education in Sub-Saharan Africa (Ahmed et al. 2009; Kinsman, Harrison, and Kengeya-Kayondo 1999; Njue et al. 2009), which identified a lack of relevant resources as major barriers of implementation. A lack of motivation among teachers who provided sexuality education after school hours has also been noted when they do not receive financial compensation for their extra work. At times, teachers have even had to use their own money to have the programme implemented. Furthermore, Rijsdijk (2013) has observed that a significant proportion of students are not able to attend all programme 
meetings. Reasons for this include the non-payment of school fees, going home to help with other priorities, doing homework and so on. This may lead teachers to have to repeat sessions and/or students missing out on one or more sessions. Overall, a whole range of major and minor factors hinder teachers from complete and faithful implementation and students from participating in the programme as intended.

Reduced programme fidelity may limit programme results. In Rijsdijk's (2013) evaluation study in Uganda, for example, a follow-up comparison between intervention schools, based on completeness of programme implementation, revealed that almost all significant positive effects disappeared in those schools that implemented less than $50 \%$ of the lessons.

\section{Teacher skills}

All the programme process evaluations indicate that teachers' motivation, attitudes and skills are essential to programme fidelity and to programme effectiveness. As other studies (e.g. Kontula 2010) have shown, being positively motivated to teach tolerant and liberal attitudes towards sexuality, being confident in talking about sexuality, and being able to employ the right teaching techniques are essential to the success of sexuality education programmes. And as all studies conclude, not least in resource poor settings, many teachers fall short on these criteria. It has already been noted that particular topics may be difficult to talk about for many teachers, and this is often due to the fact that teachers' norms and attitudes in relation to these topics are not in line with The World Starts With Me curriculum objectives. De Haas (2013) interviewed programme teachers in Uganda and noted that many are still inclined to teach abstinence, continue to use fear-based messages and have difficulty letting go of traditional cultural beliefs regarding sexuality as immoral and taboo, not least where young people and (unmarried) young people are concerned. Comparable observations have been reported from other countries. Girls are often seen as the vulnerable sex for whom teachers feel abstinence is the best option; protected sex is often seen only as a last resort rather than another option for students. Traditional gender norms are often strengthened rather than transformed through such classes.

In Uganda as well as other countries, many teachers grapple to come to terms with the conflicts they experience between teaching CSE and dominant socio-cultural and religious norms. The need for gender transformative teaching methods is endorsed by only a minority of teachers. Professional norms and identity, in addition, may require a form of teacher authority that is at odds with the participatory teaching methods proposed by the programme. De Haas (2013) noted in Uganda that many teachers feared losing respect and authority altogether when talking about sex with students. Clearly, such attitudes and norms are not conducive to the development of complex skills such as facilitatory teaching. Employing rights-based sexuality education may be especially difficult with very young adolescents. Large class sizes are another barrier to using such techniques. In addition, teachers sometimes lack the ability to manage difficult medical terminology relating to HIV/AIDS and other STIs. They may prefer a medical approach to a sexual one because it is easier to deal with and asserts their authority and status, but they may lack the required skills to approach the subject from this angle too. Specific observations such as these have been shared by several different programme implementing agencies. There is thus reason to believe that implementation experiences are, to a large extent, comparable across sites. 
What process evaluations and experiences also show is that lack of skills and the tension between personal norms and programme requirements are, to an important extent, due to a lack of training and a non-supportive school environment. In principle, all programme teachers are trained, and there is abundant evidence that they appreciate the training offered, asserting that it strengthens their motivation and makes them more confident to discuss sexuality openly with their students. However, despite positive changes, teachers still find it difficult to have a non-judgemental attitude, and to implement interactive didactics. There is evidence that teachers often relapse into pre-training modes of teaching once they are again back working on their own in a non-supportive environment. Training evaluations show that teachers would prefer to receive more training on difficult topics, as well as on the use of facilitatory techniques in order to support full student participation. Teachers may also be hindered by a high staff turnover, lack of follow-up training and lack of on the spot guidance. In particular, teachers complain about not knowing and not receiving guidelines on how exactly to adapt the programme to specific local student needs and possibilities, a shortcoming in teacher support noted in a number of other studies as well (Ott et al. 2011; Rotheram-Borus et al. 2008). These and other problems are aspects of an often generally non-supportive educational structure and cultural context.

\section{Contextual barriers}

Observations in many settings show that the school context is thus characterised by many practical and organisational barriers. In addition, the school's social climate is often at odds with what the programme aims to strengthen. Often, notably unequal, gendered treatment of students has been observed (Browes 2014). The World Starts With Me experiences are fully comparable with what Jewkes (2010) has illustrated for the MEMA kwa Vijana programme in Tanzania and Kenya, where she noted a school context of massive gender and status power differentials between teachers and learners, and where substantial risks of rape, harassment, economic exploitation and the beating of learners severely undermined positive messages from the programme. In addition, the wider normative and ideological context in many countries is also often dominated by messages of adolescent abstinence. Particularly in Uganda, Kenya and Indonesia, teachers indicated finding it difficult to implement a comprehensive programme such as The World Starts With Me that is in some respects contradictory to the abstinence-only messages, not only from their school management and other teachers in the school, but also from the national and local ministries of education (Rijsdijk 2013; de Haas, 2013). In some countries, information sharing or certain activities (e.g. condom demonstrations) may even be prohibited by law.

Limited access to good and youth friendly sexual and reproductive health and rights services and to relevant supplies is another aspect of a context that undermines programme impact. Good intentions to use condoms, for instance, are hard to put into practice in a context where condoms are not widely available at a reasonable cost. School-based efforts to provide new information to very young adolescents and encourage them to adopt healthy behaviours may also fail if boys and girls return home to conflicting messages. Besides, young people nowadays have to deal with a virtual world in which competing Internet representations of sexuality may provide environments where, in the worst case, the messages conveyed by sexuality education in schools can only really achieve a fraction of what is actually needed to substantially improve young peoples' sexual health. Many authors have 
stressed the limitations of educational programmes promoting behaviours and attitudes where application is strongly hampered by disabling normative, cultural and political environments, notably in the global South (e.g. Michielsen et al. 2012; Wood and Rolleri 2014). But the global North still experiences challenges in this respect as well. In the USA, Cavazos-Rehg et al. (2012) found that the effects of sexuality education were constrained by state-level characteristics, notably religiosity and political conservatism/abortion politics, and that state characteristics also influenced adolescent birth rates above and beyond sexuality education.

\section{Ways forward}

Lessons learned, progressive insights, a changing world and implementation of the programme among specific groups and in specific contexts make it necessary to continuously critically reflect, adapt and improve its content, approach and didactics. In 2013, The World Starts With Me was thoroughly revised based on findings from impact and process evaluations, Rutgers' experience of local implementing partners, and the available literature (e.g. Boonstra 2011; Fine and McClelland 2006; Harrison et al. 2010; Rogow et al. 2013; Spencer, Maxwell, and Aggleton 2008). Among others, the number of lessons has been reduced to increase implementation fidelity, more attention has been included for young people living with HIV, there is greater focus on social influence, media and norms, and on available support systems and youth friendly services. There is also more explicit attention to interactive methods such as modelling by peer educators and games, and more (audio) visual materials are included. Not least, more attention has been given to gender. The need to address gender power relations as part of CSE has been argued for a long time, and an actual shift towards the successful integration of gender as part of sexuality education has indeed been noted of late, for girls as well as boys (e.g. Barker, Ricardo, and Nascimento 2007; Dworkin, Fleming, and Colvin 2015; Haberland 2015; Rogow et al. 2013; UNFPA 2010; Wood and Rolleri 2014). On the basis of her comprehensive review of evaluation studies, Haberland (2015) concludes that education programmes that addressed gender or power were five times likely to be effective as those that did not.

However, even more than with respect to content, these programme aspects need to be developed by teachers who are capable of helping young people move towards empowerment rather than simply improving their knowledge or regulating their behaviours. Empowering methods need to put young people at the centre, be sensitive to (the heterogeneity of) their concerns, realities, suggestions, interests and resistance, and aim at fine-tuning a programme to fit all of these requirements. Clearly, priority number one for sexuality education is to better support teachers in being able to do so (cf. Poobalan et al. 2009). Standard The World Starts With Me implementation procedures encompass extensive teacher training, but there is much room for improvement and intensification in this respect. The ideal form of teacher training is a continuous process which includes coaching and provides guidelines on how to successfully adapt a programme to local needs, groups and contexts (cf. Rotheram-Borus, Ingram, and Flannery 2008). As part of The World Starts With Me, a teacher refresher course and the establishment of a community of users are being developed with the aim to meet such needs. Teacher performance can further be enhanced by a supportive overall school context. The prevention of school-based gender-based violence and the promotion of safe learning environments are priorities in this respect. 
It is essential that sexuality education efforts are further complemented by a sexual and reproductive health system that provides young people with the adequate and high quality services and supplies they need, both in- and out of school (WHO 2002). It is becoming apparent that, in sexual health, a multicomponent approach is required that complements school-based sexuality education with youth friendly sexual health services in an overall enabling (community) environment. Both in HIV and in sexual and reproductive health and rights programming, evidence for the effectiveness of 'combination prevention' and multilevel approaches is clear (Auerbach, Parkhurst, and Cáceres 2011; Bearinger et al. 2007; Lloyd 2010). Routes to access young people in- or outside the school context alongside teacher-led, class-based education should be intensively explored. In its own work, Rutgers is presently investigating different means of youth access to sexual and reproductive health and rights information. Particularly interesting are electronic and mobile health strategies, such as the use of online channels (websites and social media) and mobile phone platforms (including helplines, SMS or chat). Initial evidence of the applicability and effectiveness of such strategies in addition to class-based WSWM implementation is promising, not least with respect to reaching hard-to-reach groups. In Uganda and West-Kenya, a pilot with 'old-fashioned' newspaper pull-outs, that the local Straight Talk project helps young people make themselves, has been implemented. Preliminary results from an evaluation by the Centre for the Study of Adolescence in Nairobi suggest that discussion of the pull-outs in peer-led groups is highly appreciated by students and that the pull-outs are read by many non-programme participant students as well, thereby increasing reach.

Programme fidelity, teacher performance and programme effectiveness all profit enormously when sexuality education is structurally embedded in the official school curriculum and does not need to be provided in after-school hours with little organisational support. Advocacy to that end among local and national authorities and governing structures is highly desirable. Recently in East and Southern Africa, UNESCO successfully mobilised substantial high-level political support for the improved provision of sexuality education and sexual and reproductive health services for young people. In December 2013, in Cape Town, 20 Ministers of Health and Education from the region affirmed their commitment. However, implications related to inclusion of sexual diversity (LGBTQ) issues have not been addressed in these commitments due to social and cultural constraints. There is therefore a need for ongoing advocacy to influence future policies that will be more inclusive of rights for all. In advocating for structural implementation of sexuality education, possibilities in terms of breadth of reach vs. the comprehensiveness of programmes will always have to be carefully considered.

The complexity of implementation and delivery processes requires a coherent and holistic approach. A so-called 'whole school approach' (Buijs 2009; Schaalma et al. 2004; Young, St Leger, and Buijs 2013) is widely used by health promoting schools and goes beyond classroom teaching to also address supportive school policies and environments, links with parents and community, and collaboration with health organisations. Ownership is fostered by involving all relevant stakeholders, from school boards to students, government officials to peer educators and teachers to service providers in the implementation of a coherent set of multiple interventions, based on a clear needs assessment. While on the one hand a whole school approach sounds deceptively simple, 'the practice is complex, dynamic and dependent on the context in which it is embedded' (Buijs 2009, 7). At present, Rutgers and partner organisations are piloting and documenting a whole school approach for sexuality 
education in ten schools in Kenya and Uganda, with the aim of including more pupils per school, reaching them earlier and developing a cost-effective, scalable implementation model. With the coaching support of the partner organisations, schools are facilitated in taking the lead in designing feasible interventions, making the best possible use of available school budgets, staff, relationships and resources in order to overcome challenges. The project will deliver a manual for schools and for intermediary organisations containing guidelines and suggestions on how sexuality education can be implemented with a minimum of outside support. Combined with support from local governments, these schools will become advocates for other schools and further bring CSE to scale. Clearly, large-scale implementation is desirable, if only because pilot implementation with a relatively small reach has been shown to be costly and therefore not cost-effective in the long run (e.g. Kivela, Ketting, and Baltussen 2011).

\section{Conclusion}

This paper has addressed some of the difficulties surrounding implementation of schoolbased sexuality education as illustrated by a decade's experience in implementing CSE in a number of countries in Africa and Asia. Most of our observations are not new, but they remain highly relevant. They are also consistent with findings in a recent analysis by Chandra-Mouli, Lane, and Wong (2015), who argue that adolescent sexual and reproductive health sadly suffers from interventions such as CSE being delivered ineffectively. The fact that many studies still find evidence for effectiveness despite implementation challenges, provides an all the more strong argument in favour of sexuality education's potential. Ways forward include the further advancement of programmes towards gender transformativity and empowerment and improved engagement with normative and practical barriers, a far-reaching expansion of comprehensive teacher training and coaching, and a serious scale-up of multilevel and whole school approaches. Ultimately, school ownership of programmes is a key requirement for sustainability and the context of school-based sexuality education needs as much attention as programmes themselves. The implementation of sexuality education could profit from a vision of sexual health as not as much an outcome as it is a process, a complex process of ongoing interaction between individuals and their social environments and overall possibilities.

\section{Notes}

1. A protocol for the planning and development of evidence-based health promotion interventions, see Leerlooijer et al. (2011).

2. Dotted line is implicitly discussed in this paper; the figure is a simplification, various lines (e.g. from teacher and school level to student level) are not included, as they are not discussed in the paper.

\section{Disclosure statement}

No potential conflict of interest was reported by the authors. 


\section{Funding}

This work was supported by funding from the Dutch Ministry of Foreign Affairs.

\section{References}

Ahmed, N., A. J. Flisher, C. Mathews, W. Mũkoma, and S. Jansen. 2009. "HIV Education in South African Schools: The Dilemma and Conflicts of Educators." Scandinavian Journal of Public Health 37 (2 Suppl): 48-54.

Auerbach, J. D., J. O. Parkhurst, and C. F. Cáceres. 2011. "Addressing Social Drivers of HIV/AIDS for the Long-Term Response: Conceptual and Methodological Considerations." Global Public Health 6 (3 Suppl): S293-S309.

Barker, G., C. Ricardo, and M. Nascimento. 2007. Engaging Men and Boys in Changing Gender-Based Inequity in Health: Evidence from Interventions. Geneva: World Health Organization (WHO) and Promundo Institute.

Bearinger, L. H., R. E. Sieving, J. Ferguson, and V. Sharma. 2007. “Global Perspectives on the Sexual and Reproductive Health of Adolescents: Patterns, Prevention, and Potential." The Lancet 369: 1220-1231.

Boonstra, H. D. 2011. "Advancing Sexuality Education in Developing Countries: Evidence and Implications." Guttmacher Policy Review 14 (3): 17-23.

Bromnick, R., and P. Swinburn. 2003. "Young People's Social Representations of a Sexual Experience." Journal of Adolescence 26: 375-379.

Browes, N. 2014. "The Strategies of Teachers and Students in Sexuality Education. The Case of One School-Based Programme in Ethiopia." Masters thesis, University of Amsterdam.

Buijs, G. J. 2009. "Better Schools through Health: Networking for Health Promoting Schools in Europe." European Journal of Education 44 (4): 507-520.

Cavazos-Rehg, P. A., M. J. Krauss, E. L. Spitznagel, M. Iguchi, M. Schootman, L. Cottler, R. A. Grucza, and L. J. Bierut. 2012. "Associations between Sexuality Education in Schools and Adolescent Birthrates: A State-Level Longitudinal Model." Archives of Pediatrics \& Adolescent Medicine 166 (2): 134-140.

Chandra-Mouli, V., C. Lane, and S. Wong. 2015. "What Does Not Work in Adolescent Sexual and Reproductive Health: A Review of Evidence on Interventions Commonly Accepted as Best Practices." Global Health: Science and Practice 3 (3): 333-340.

Cushman, N., L. M. Kantor, E. Schroeder, L. Eicher, and G. Gambone. 2014. "Sexuality Education: Findings and Recommendations from an Analysis of 10 United States Programmes." Sex Education 14 (5): 481-496.

Doyle, A. M., D. A. Ross, K. Maganja, K. Baisly, C. Masesa, A. Andreasen, M. L. Plummer, A. I. Obasi, H. A. Weiss, S. Kapiga, D. Watson-Jones, J. Changalucha and H.J. Hayes for the MEMA kwa Vijana Trial Study Group. 2010. "Long-Term Biological and Behavioural Impact of an Adolescent Sexual Health Intervention in Tanzania: Follow-up Survey of the Community-Based MEMA Kwa Vijana Trial." PLoS Medicine 7 (6): e1000287.

Dworkin, S. L., and A. A. Ehrhardt. 2007. “Going beyond 'ABC' to Include 'GEM': Critical Reflections on Progress in the HIV/AIDS Epidemic." American Journal of Public Health 97: 13-18.

Dworkin, S. L., P.J. Fleming, and C. J. Colvin. 2015. "The Promises and Limitations of Gender-Transformative Health Programming with Men: Critical Reflections from the Field." Culture, Health \& Sexuality. doi:10.1080/13691058.2015.1035751.

van Enck, Jorik. 2011. "Evaluation of a Comprehensive SRHR Curriculum for Primary Schools." Masters thesis, University of Amsterdam.

Fine, M., and S. I. McClelland. 2006. "Sexuality Education and Desire: Still Missing after All These Years." Harvard Educational Review 76 (3): 297-338.

Germain, A., R. Dixon-Mueller, and G. Sen. 2009. "Back to Basics: HIV/AIDS Belongs with Sexual and Reproductive Health." Bulletin of the World Health Organization 87: 840-845.

de Haas, B. 2013. Teachers and Sexuality Education in Urban Secondary Schools in Uganda. Preliminary Findings. Groningen: University of Groningen. 
Haberland, Nicole A. 2015. "The Case for Addressing Gender and Power in Sexuality and HIV Education: A Comprehensive Review of Evaluation Studies." International Perspectives on Sexual and Reproductive Health 41 (01): 031-042.

Haberland, N., and D. Rogow. 2015. "Sexuality Education: Emerging Trends in Evidence and Practice." Journal of Adolescent Health 56 (1): S15-S21.

Harrison, A., M. Newell, J. Imrie, and G. Hoddinott. 2010. "HIV Prevention for South African Youth: Which Interventions Work? A Systematic Review of Current Evidence." BMC Public Health 10: 102.

Iyer, P., D. Clarke, and P. Aggleton. 2014. "Barriers to HIV and Sexuality Education in Asia." Health Education 114 (2): 118-132.

Jewkes, R. 2010. "Where to for Sexual Health Education for Adolescents in Sub-Saharan Africa?" PLoS Medicine 7 (6): e1000288.

Kincheloe, Joe L. 2008. Knowledge and Critical Pedagogy. New York: Peter Lang Publishing.

Kinsman, J., S. Harrison, J. Kengeya-Kayondo. 1999. "Implementation of a Comprehensive AIDS Education Programme for Schools in Masaka District, Uganda." AIDS Care 11 (5): 591-601.

Kippax, S. 2003. "Sexual Health Interventions Are Unsuitable for Experimental Evaluation." In Effective Sexual Health Interventions. Issues in Experimental Evaluation, edited by J. M. Stephenson, J. Imrie and C. Bonell, 17-35. Oxford: Oxford University Press.

Kirby, D. 2007. "Sex and HIV Education Programs: Their Impact on Sexual Behaviors of Young People throughout the World." Journal of Adolescent Health 40: 206-217.

Kirby, D. 2008. "The Impact of Abstinence and Comprehensive Sex and STD/HIV Education Programs on Adolescent Sexual Behavior." Sexuality Research \& Social Policy 5: 18-27.

Kirby, D. 2011. Sex Education: Access and Impact on Sexual Behaviour of Young People. New York: United Nations.

Kivela, J., E. Ketting, and R. Baltussen. 2011. Cost and Cost-Effectiveness Analysis of School-Based Sexuality Education Programmes in Six Countries. Paris: UNESCO.

Kohler, P. K., L. E. Manhart, and W. E. Lafferty. 2008. “Abstinence-Only and Comprehensive Sex Education and the Initiation of Sexual Activity and Teen Pregnancy." Journal of Adolescent Health 42: 344-351.

Kontula, O. 2010. "The Evolution of Sex Education and Students' Sexual Knowledge in Finland in the 2000s." Sex Education 10: 373-386.

Leerlooijer, J. N. 2013. "About Goats, Girls, Boys and the Bees. Promoting Adolescents' Sexual and Reproductive Health and Rights in Uganda, Indonesia and Thailand; an Intervention Mapping Approach." PhD diss., Maastricht University.

Leerlooijer, J. N., R. A. Ruiter, J. Reinders, W. Darwisyah, G. Kok, and L. K. Bartholomew. 2011. "The World Starts with Me: Using Intervention Mapping for the Systematic Adaptation and Transfer of School-Based Sexuality Education from Uganda to Indonesia." Translational Behavioral Medicine 1 (2): 331-340.

Lesko, N. 2010. "Feeling Abstinent? Feeling Comprehensive? Touching the Affects of Sexuality Curricula." Sex Education 10: 281-297.

van Lieshout, S. 2013. "Explaining Non-Findings in Kenyan the World Starts with Me Evaluation." Masters thesis, Maastricht University.

Lloyd, C.B. 2010. "The Role of Schools in Promoting Sexual and Reproductive Health among Adolescents in Developing Countries." In Social Determinants of Sexual and Reproductive Health. Informing Future Research and Programme Implementation, edited by S. Malarcher, 113-132. Geneva: WHO.

McCave, E. L. 2007. “Comprehensive Sexuality Education Vs. Abstinence-Only Sexuality Education:The Need for Evidence-Based Research and Practice." School Social Work Journal 32 (1): 14-28.

Michielsen, K., M. F. Chersich, S. Luchters, P. De Koker, R. Van Rossem, and M. Temmerman. 2010. "Effectiveness of HIV Prevention for Youth in Sub-Saharan Africa: Systematic Review and MetaAnalysis of Randomized and Nonrandomized Trials." AIDS 24: 1193-1202.

Michielsen, K., M., Chersich, M., Temmerman, T. Dooms, R. van Rossem. 2012. "Nothing as Practical as a Good Theory? The Theoretical Basis of HIV Prevention Interventions for Young People in Sub-Saharan Africa: A Systematic Review." AIDS Research and Treatment. pp. 18. Article ID 345327. doi:10.1155/2012/345327.

Njue, C., C. Nzioka, B. M. Ahlberg, A. M. Pertet, and H. A. C. M. Voeten. 2009. “'If You Don't Abstain, You Will Die of AIDS': AIDS Education in Kenyan Public Schools." AIDS Education and Prevention 21 (2): 169-179. 
Ott, M. A., M. Rouse, J. Resseguie, H. Smith, and S. Woodcox. 2011. “Community-Level Successes and Challenges to Implementing Adolescent Sex Education Programs." Maternal and Child Health Journal 15: 169-177.

Poobalan, A. S., E. Pitchforth, M. Imamura, J. S. Tucker, K. Philip, J. Spratt, L. Mandava, and E. van Teijlingen. 2009. “Characteristics of Effective Interventions in Improving Young People's Sexual Health: A Review of Reviews." Sex Education 9 (3): 319-336.

Power, Lorna, and Cohen Joseph. 2005. Competency-Based Education and Training Delivery: Status, Analysis and Recommendations. Jakarta: USAID Indonesia, DBE3, Save the Children, AED, IRD.

Rana, I., ed. 2014. Most Significant Change Stories from Pakistan. Quetta: Rutgers WPF Pakistan under UFBR Programme.

Rijsdijk, L. E. 2013. "The World Starts with Me: Promoting Sexual and Reproductive Health and Rights of Adolescents in Uganda." PhD diss., Maastricht University.

Rijsdijk, E. L., R. Lie, A. E. R. Bos, J. N. Leerlooijer, and G. Kok. 2013. "Sexual and Reproductive Health and Rights: Implications for Comprehensive Sex Education among Young People in Uganda." Sex Education 13 (4): 409-422.

Rogow, D., N. Haberland, A. Del Valle, and M. Skaer. 2013.“Integrating Gender and Rights into Sexuality Education: Field Reports on Using It's All One." Reproductive Health Matters 21 (41): 154-166.

Rutgers. 2014. "The World Starts with ..." http://www.rutgers.international/node/738?des tination=node/623.

Rotheram-Borus, M. J., B. L. Ingram, and D. Flannery. 2008. “Common Principles in Effective Adolescent HIV Prevention Programs." AIDS and Behavior 12: 374-383.

Rotheram-Borus, M. J., D. Swendeman, and D. Flannery. 2009. "Family Wellness, Not HIV Prevention." AIDS and Behavior 13: 409-413.

Rutgers, W. P. F. 2011. WSWM Overall Report: Evaluation of the Comprehensive, Rights-Based Sexuality Education Programme 'The World Starts with Me' in Uganda, Kenya, Indonesia and Thailand. Utrecht: Rutgers WPF.

Schaalma, H., J. Reinders, M. Matasu, S. Kaaya, and K. Klepp. 2004. “When the Researchers Have Gone Home to Write Their Articles. Diffusion and Implementation of School-Based HIV-Prevention Programs in Tanzania." East African Journal of Public Health 1 (1): 24-32.

Schutte, L., R. M. Meertens, F. E. F. Mevissen, S. Meijer, G. Kok, and H. P. Schaalma. 2014. “Long Live Love. the Implementation of a School-Based Sex-Education Program in the Netherlands." Health Education Research 29 (4): 583-597.

Spencer, G., C. Maxwell, and P. Aggleton. 2008. “What Does 'Empowerment'Mean in School-Based Sex and Relationships Education?" Sex Education 8: 345-356.

van de Stok, L. 2014. "Exploring the Effect of College Environments on Implementation Fidelity of the Pilot 'World Starts with Me' Programme in Malawi." Masters thesis, University Amsterdam.

Trenholm, C., B. Devaney, K. Fortson, L. Quay, J. Wheeler, and M. Clark. 2007. Impacts of Four Title V, Section 510 Abstinence Education Programs. Princeton, NJ: Mathematica Policy Research.

UN. 2006. "World Population Prospects. The 2006 Revision." http://www.un.org/esa/population/ publications/wpp2006/wpp2006.htm.

Underhill, K., P. Montgomery, and D. Operario. 2007. “Sexual Abstinence Only Programmes to Prevent HIV Infection in High Income Countries: Systematic Review." BMJ 335: 248.

UNESCO. 2009. International Technical Guidance on Sexuality Education: An Evidence-Informed Approach for Schools, Teachers and Health Educators. Paris: UNESCO with UNAIDS, UNFPA, UNICEF and WHO.

UNFPA. 2010. Comprehensive Sexuality Education: Advancing Human Rights, Gender Equality and Improved Sexual and Reproductive Health. A Report on an International Consultation to Review Current Evidence and Experience. New York, NY: UNFPA.

UNFPA. 2014. State of World Population 2014: The Power of 1.8 Billion: Adolescents, Youth, and the Transformation of the Future. New York, NY: UNFPA.

UNICEF. 2014. "Generation 2030." Accessed September 3, 2014. http://data.unicef.org/gen2030/

Vanwesenbeeck, Ine. 2011. "Effective Sex-Ed. Confessions by a Believer." Paper presented at the 20th World Congress for Sexual Health, Glasgow, June 12-16, 2011.

WHO. 2002. "Adolescent Friendly Health Services: An Agenda for Change." http://www.who.int/ maternal_child_adolescent/documents/fch_cah_02_14/en/. 
WHO. 2011. WHO Guidelines on Preventing Early Pregnancy and Poor Reproductive Outcomes among Adolescents in Developing Countries. Geneva: World Health Organisation.

Wood, L., and L. A. Rolleri. 2014. "Designing an Effective Sexuality Education Curriculum for Schools: Lessons Gleaned from the South(Ern) African Literature." Sex Education 14 (5): 525-542.

Yankah, E., and P. Aggleton. 2008. "Effects and Effectiveness of Life Skills Education for HIV Prevention in Young People." AIDS Education \& Prevention 20: 465-485.

Young, I., L. St Leger, and G. Buijs. 2013. School Health Promotion: Evidence for Effective Action. Utrecht: CBO. 